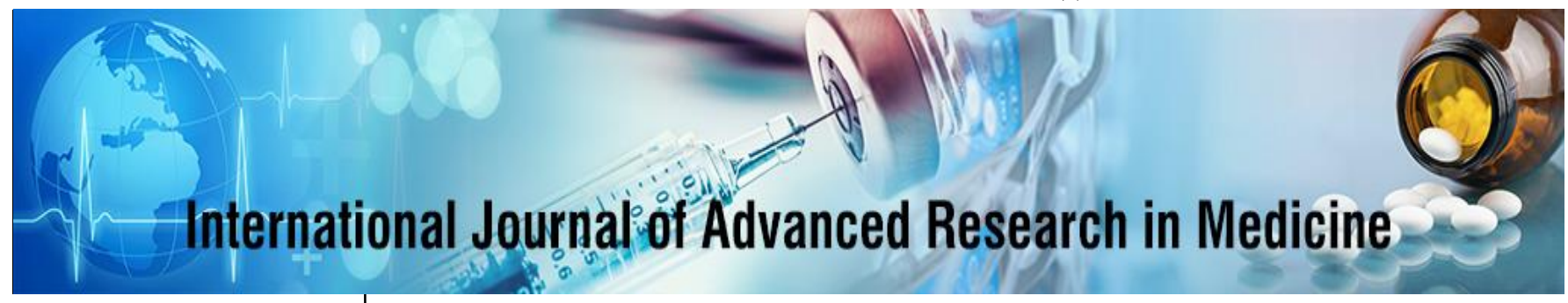

E-ISSN: 2706-9575

P-ISSN: 2706-9567

IJARM 2021; 3(1): 75-77

Received: 25-11-2020

Accepted: 02-12-2020

Shirish D Chavan

Associate professor,

Department of Tuberculosis

and Chest diseases, PIMS\&R,

Islampur, Maharashtra, India

Vijay S Patil

Professor, Department of

Community medicine,

PIMS\&R, Islampur,

Maharashtra, India

Basanagouda K Patil Associate professor,

Department of Community medicine, PIMS\&R, Islampur,

Maharashtra, India
Corresponding Author:

Basanagouda K Patil

Associate professor,

Department of Community medicine, PIMS\&R, Islampur,

Maharashtra, India

\section{Comparison of thoracic dimensions of chronic obstructive pulmonary disease patients and healthy controls: A cross-sectional study}

\author{
Shirish D Chavan, Vijay S Patil and Basanagouda K Patil
}

DOI: $\underline{\text { https://doi.org/10.22271/27069567.2021.v3.i1b.105 }}$

\begin{abstract}
Background: Chronic obstructive pulmonary disease (COPD), is a heterogeneous collection of diseases with differing causes and pathogenic mechanisms. The present study was conducted to compare thoracic dimensions between normal and COPD subjects.

Materials \& Methods: 70 patients with COPD and 70 healthy subjects were included in 2 groups. Group I were COPD patients and group II were healthy subjects. Average transverse rib cage diameter, HDI and pulmonary function tests were compared.

Results: The mean AP diameter in group I was $10.9 \mathrm{~mm}$ and in group II was $9.1 \mathrm{~mm}$, transverse diameter was $22.7 \mathrm{~mm}$ in group I and $21.0 \mathrm{~mm}$ in group II and HDI was $23.7 \mathrm{~mm}$ in group I and 20.1 $\mathrm{mm}$ in group II. The mean FEV1 in group I was $54.1 \%$ and in group II was 89.2 , FVC was 47.4 in group I and 91.5 in group II and FEV $1 / \mathrm{FVC}$ was 42.6 in group I and $97.2 \%$ in group II. The difference was statistically significant $(P<0.05)$.

Conclusion: Thoracic dimensions were increased in COPD patients as compared to healthy subjects.
\end{abstract}

Keywords: COPD, Chest, Rib, Thoracic dimension

\section{Introduction}

Chronic obstructive pulmonary disease (COPD) is a one of the most common chronic respiratory conditions that presents with significant airflow limitation after exposure to harmful particles and gases and it usually worsens with time. However, it is easily preventable and manageable if correct measures taken in time. Symptoms are primarily chronic and include dyspnea, cough, and sputum production. Chronic obstructive pulmonary disease (COPD), a heterogeneous collection of diseases with differing causes, pathogenic mechanisms, and physiological effects is one of the leading causes of death worldwide ${ }^{[1]}$. This marked heterogeneity impedes identification of subpopulations at risk for accelerated progression, thwarting therapeutic advances. Most COPD studies have included populations with mean ages older than 60 years. Chronic obstructive pulmonary disease (COPD) is characterized by airflow obstruction with chronic cough with expectoration, exertional dyspnea and wheeze. The mortality due to COPD is rising, and it is expected to become the third leading cause of death globally by $2030^{[2]}$. Among COPD due to hyperinflation, the diaphragm is flatter and lower than in normal subjects and the size of the zone of apposition is reduced. Consequently, the expansion of the lower rib cage caused by diaphragmatic contraction is lesser than in normal subjects ${ }^{[3]}$. In the most severe cases of hyperinflation, the diaphragm fibres at their origin on the ribs run transversally inward rather than cranially. In this condition, the contraction of the diaphragm causes a decrease in the transverse diameter of the lower rib cage or in the volume of the lower rib cage ${ }^{[4]}$. The present study was conducted to compare thoracic dimensions between normal and COPD subjects.

\section{Materials \& Methods}

The present study was conducted among 70 patients with COPD and 70 healthy subjects of both genders in PIMS\&R hospital, Islampur in 2020. All were informed regarding the study and their written consent was obtained. Data related to patients such as name, age, gender etc. was recorded. Patients were divided into 2 groups. Group I were treated with COPD patients and group II were healthy subjects. 
A through clinical examination was performed. Average antero-posterior rib cage diameter was taken from bases of 5th 7 th 9 th thoracic vertebrae. Average transverse rib cage diameter obtained from average of the maximal internal diameter of chest well at the level of 3rd, 6th, 9th pair of ribs, and average vertical height of the diaphragm from the base of $\mathrm{T} 1$ to the silhouette of the left and right diaphragmatic domes midway between the internal aspect of chest wall at the level of the 9th rib and the centre of the thoracic spine. Pulmonary function tests were also compared. Results thus obtained were subjected to statistical analysis in MS-Excel software. A P-value less than 0.05 was considered for statistical significance.

\section{Results}

The COPD group had 43 males (61.4\%) and 27 females (38.6\%). The comparison healthy group had 40 males $(57.1 \%)$ and 30 females $(42.9 \%)$. Table 1 shows that the mean AP diameter in group I was $10.9 \mathrm{~mm}$ and in group II was $9.1 \mathrm{~mm}(\mathrm{P}=0.01)$, transverse diameter was $22.7 \mathrm{~mm}$ in group I and $21.0 \mathrm{~mm}$ in group II (P-0.02) and HDI was 23.7 $\mathrm{mm}$ in group I and $20.1 \mathrm{~mm}$ in group II $(\mathrm{P}<0.05)$. In all the three dimensions the differences were statistically significant $(P<0.05)$. Table 2 shows that mean FEV1 in group I was $54.1 \%$ and in group II was $89.2 \%(\mathrm{P}=0.04)$, FVC was $47.4 \%$ in group I and $91.5 \%$ in group II $(\mathrm{P}=0.01)$ and $\mathrm{FEV} 1 / \mathrm{FVC}$ was $42.6 \%$ in group I and $97.2 \%$ in group II $(\mathrm{P}=0.01)$. The differences were statistically significant $(P<0.05)$.

Table 1: Comparison of thoracic dimensions (N-140)

\begin{tabular}{|c|c|c|c|}
\hline Thoracic dimensions (mm) & Group I & Group II & P value \\
\hline AP diameter & 10.9 & 9.1 & 0.01 \\
\hline Transverse diameter & 22.7 & 21.0 & 0.02 \\
\hline HDI & 23.7 & 20.1 & 0.05 \\
\hline
\end{tabular}

Table 2: Comparison of pulmonary function tests in COPD vs Healthy controls (N-140)

\begin{tabular}{|c|c|c|c|}
\hline Pulmonary function tests & Group I & Group II & P value \\
\hline FEV 1 & 54.1 & 89.2 & 0.04 \\
\hline FVC & 47.4 & 91.5 & 0.01 \\
\hline FEV 1/FVC & 42.6 & 97.2 & 0.01 \\
\hline
\end{tabular}

\section{Discussion}

COPD is a progressive disease and can be attributed to initial complex biochemical and cellular events in the small airways and surrounding alveoli. Alveolar destruction with emphysema is one of the features of COPD ${ }^{[5]}$. Scanning electron microscopic examination of emphysematous lung sections demonstrate characteristic destruction of tissue, loss and collapse of regularly shaped alveoli, and enlarged alveolar ducts. In a vast majority of COPD cases, lowered recoil with limited expiration flow eventually causes hyperinflation and worsening of lungs. In COPD lung hyperinflation alters chest wall geometry and, as a consequence, chest wall function. Several western studies have reported alterations in thoracic geometry and dimensions in COPD patients but very few Indian studies were done in alterations in thoracic dimensions among COPD ${ }^{[6]}$. COPD is greatly under-diagnosed, as indicated by data from the Third National Health and Nutrition Examination Study. These data suggest that over $63 \%$ of adults with evidence of impaired lung function have never been diagnosed with a lung disease. Other lines of research have also demonstrated that many cases are first diagnosed at the time of an acute exacerbation of COPD. Early detection and cost-effective treatment of COPD cases plays a vital role in clinical outcomes peripheral health care settings. Therapeutic options exist to treat COPD, with the greatest therapeutic benefit likely to be in symptomatic individuals with a forced expiratory volume in 1 second (FEV1) ${ }^{[7]}$.

In present study, group I had 43 males and 27 females and group II had 40 males and 30 females. Kilburn et al., ${ }^{[8]}$ compared the thoracic dimensions Antero posterior [AP] diameter, Transverse diameter and Height of diaphragm (HDI) between COPD patients and healthy controls. COPD cases showed higher average AP diameter $(10.64 \mathrm{cms} \pm$ $2.16 \mathrm{cms})$ compared to healthy controls $(9.29 \mathrm{cms} \pm$ $1.47 \mathrm{cms})$. This difference was statistically significant (P $<0.001)$. We observed that mean AP diameter in COPD patients was $10.9 \mathrm{~mm}$ and in healthy controls it was $9.1 \mathrm{~mm}$, transverse diameter was $22.7 \mathrm{~mm}$ in COPD group and 21.0 $\mathrm{mm}$ in controls and HDI was $23.7 \mathrm{~mm}$ in COPD group and $20.1 \mathrm{~mm}$ in controls. Dransfield MT et al. ${ }^{[9]}$ revealed that at all stages of COPD severity, men had more CT emphysema than women. COPD in women is distinct from that in men with respect to phenotype, symptom burden, and comorbidities. Women are more predisposed to develop chronic bronchitis, have more dyspnea, and suffer more frequently from coexistent anxiety or depression.

We found that mean FEV 1 in group I was $54.1 \%$ and in group II was $89.2 \%$, FVC was $47.4 \%$ in group I and $91.5 \%$ in group II and FEV1/FVC was 42.6 in group I and 97.2 in group II. Lim et al. ${ }^{[10\}}$ enrolled 85 patients with COPD and 30 normal controls. Thoracic cage dimensions were measured using chest computed tomography at levels 3, 6, and 9 of the thoracic spine. They measured the maximal transverse diameter, mid-sagittal antero-posterior (AP) diameter, and maximal AP diameter of the right and left hemithorax. The average AP diameter was significantly greater in patients with COPD compared with normal controls $(13.1 \pm 2.8 \mathrm{~cm}$ vs. $12.2 \pm 1.13 \mathrm{~cm}$, respectively; $\mathrm{p}=0.001)$. The ratio of $\mathrm{AP} /$ transverse diameter of the thoracic cage was also significantly greater in patients with COPD compared with normal controls $(0.66 \pm 0.061$ vs. $0.61 \pm 0.86 ; \mathrm{p}=0.002)$. In COPD patients, the AP diameter of the thoracic cage was positively correlated with body mass index (BMI) and 6-minute walk test distance. If changes in the thoracic cage are reflective of the degree of hyperinflation, which is associated with more severe airflow obstruction, it is generally a more structural change in patients with COPD. Other studies have reported an increase in the AP diameter of the thorax in patients with COPD compared with normal subjects, especially in the lower part of the thoracic cage, when examined at the level of functional residual capacity ${ }^{[11,12]}$.

\section{Conclusion}

Authors found that thoracic dimensions were increased in COPD patients as compared to healthy subjects.

\section{References}

1. McDonough JE, Yuan R, Suzuki M, Seyednejad N, Elliott WM, Sanchez PG, et al. Small-airway obstruction and emphysema in chronic obstructive pulmonary disease. N Engl J Med 2011;365:1567-75. 
2. Stubbing DG, Mathur PN, Roberts RS, Campbell EJ. Some physical signs in patients with chronic airflow obstruction. Am Rev Respir Dis 1982;125:549-52.

3. Decramer M. Hyperinflation and respiratory muscle interaction. Eur Respir J 1997;10:934-41.

4. Yin P, Zhang M, Li Y, Jiang Y, Zhao W. Prevalence of COPD and its association with socioeconomic status in China: findings from China Chronic Disease Risk Factor Surveillance 2007. BMC Public Health 2011;11:586.

5. Gilmartin JJ, Gibson GJ. Abnormalities of chest wall motion in patients with chronic airflow obstruction. Thorax 1984;39:264-71.

6. Hogg JC, Chu F, Utokaparch S, Woods R, Elliott WM, Buzatu L, et al. The nature of small-airway obstruction in chronic obstructive pulmonary disease. $\mathrm{N}$ Engl J Med 2004;350:2645-53.

7. Aliverti A, Quaranta M, Chakrabarti B, Albuquerque ALP, Calverley PM. Paradoxical movement of the lower ribcage at rest and during exercise in COPD patients. Eur Respir J 2009;33:49-60.

8. Kilburn KH, Asmundsson T. Anteroposterior chest diameter in emphysema: from maxim to measurement. Arch Intern Med 1969;123:379-82.

9. Dransfield MT, Washko GR, Foreman MG, Estepar RS, Reilly J, Bailey WC. Gender differences in the severity of CT emphysema in COPD. Chest 2007;132:464-70.

10. Lim SJ, Kim JY, Lee SJ, Lee GD, Cho YJ, Jeong YY, Jeon KN, Lee JD, Kim JR, Kim HC. Altered thoracic cage dimensions in patients with chronic obstructive pulmonary disease. Tuberculosis and respiratory diseases 2018;81(2):123.

11. Gilmartin JJ, Gibson GJ. Abnormalities of chest wall motion in patients with chronic airflow obstruction. Thorax 1984;39:264-71.

12. Raghavan D, Varkey A, Bartter T. Chronic obstructive pulmonary disease: the impact of gender. Curr Opin Pulm Med 2017;23:117-23. 